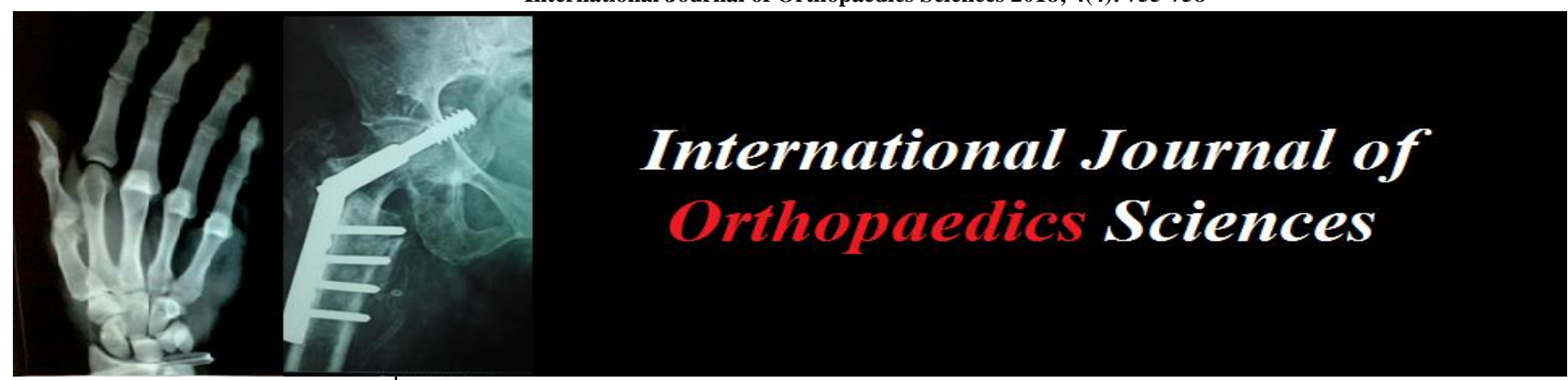

ISSN: $2395-1958$

IJOS 2018; 4(4): 755-758

(C) 2018 IJOS

www.orthopaper.com

Received: 09-08-2018

Accepted: 13-09-2018

Satya Prasanna Nayak

Associate Professor, Department of Orthopaedics and

Traumatology, SLN Medical

College, Koraput, Odisha, India

Chandan Kumar Panda

PG from Department Of

Orthopaedics, MKCG Medical

College, Berhampur, Odisha,

India
Correspondence

Chandan Kumar Panda

PG from Department Of

Orthopaedics, MKCG Medical

College, Berhampur, Odisha,

India

\section{Surgical treatment of girdle bone osteochondroma: A case series}

\section{Satya Prasanna Nayak and Chandan Kumar Panda}

DOI: https://doi.org/10.22271/ortho.2018.v4.i4j.94

\section{Abstract}

Background: Osteochondroma is most common benign bone tumour. But flat bones are rarely involved. Objective of study is to present 10 cases of osteochondroma in girdle bone that is rarely reported in medical literature and addressing specific concerns with these entities.

Methods: This is a case series which described 10 cases having osteochondroma in pubic bone ( 2 cases) and scapula (8 cases). Patients coming to the Orthopaedics Department of MKCG Medical College, Berhampur between December 2015 to December 2017 were included in case series and those were severely ill and did not give consent were excluded.

Results: Age of patients ranged from 15 to 46 years. Patients with pubic bone osteochondroma presented with swelling and dull aching, non radiating pain. Patients with scapular bone osteochondroma presented with swelling on dorsal surface of scapular body, out of which 3 had towards lateral border and 5 towards medial border.5 patients were complaining of mild pain. For pubic bone osteochondroma, under spinal anesthesia and supine position a curvilinear suprapubic incision (Like pfannenstiel approach) was given and bony mass was excised at base of outgrowth from parent bone. Similarly for osteochondroma in scapula, longitudinal incision was given over the involved area and mass was excised at base of outgrowth from parent bone. Both intra operative and post operative periods were uneventful. In all cases, patients were doing normal activity without any complain at 3 weeks and 6 weeks of follow up period. The histopathological findings of the excised mass corresponded to the findings of osteochondroma.

Conclusion: This case series described rare cases of osteochondroma in scapula and pubic bone. Surgical excision of the masses was done which showed good result for the osteochondroma.

Keywords: osteochondroma, neoplasm, case series, exostosis

\section{Introduction}

Osteochondromas are the most common benign bone tumors ${ }^{[1,2]}$. They represent about $35 \%$ of benign and $8 \%$ of all bone tumors, which are often underestimated since majority are asymptomatic ${ }^{[3]}$. Osteochondromas mostly affect long bones. Flat bones like scapula and pelvic bone are rarely involved. Pelvic osteochondroma accounts for $5 \%$ [3] of all osteochondroma, out of which pubic bone involvement is very rare ${ }^{[4]}$ and is not documented till now. Scapular osteochondroma has a 3 to $4.6 \%$ rate of involvement ${ }^{[3]}$. There are few case reports which described pubic and scapula bone osteochondroma. Osteochondroma are due to aberrant growth of the normal epiphyseal growth plate cartilage.

The objective of this case series is to present 10 cases of osteochondroma in girdle bone that is rarely reported in medical literature and addressing specific concerns with these entities.

\section{Methods}

This study is a case series in which 10 cases having osteochondroma in pubic bone ( 2 cases) and scapula (8 cases) were described. Patients with osteochondroma in pubic bone and scapula bone coming to the Orthopedics Department of MKCG Medical College, Berhampur between December 2015 to December 2017 were included in the case series. Patients who were severely ill and did not give consent were excluded from the study. 


\section{Case presentation}

\section{Pubic bone osteochondroma}

We described 2 cases of pubic bone osteochondroma. 2 cases were female, one aged 40 years and another aged 33 years. Both presented with swelling and dull aching, non radiating pain over pubic region. Pain increased with activity. In both cases mass is in right pubic bone which was confirmed by $\mathrm{X}$ ray. All the required investigations like $\mathrm{x}$ ray, CT scan, Routine bone and cardiological investigation were done before surgery. All clinical examination and radiological investigation were suggestive of osteochondroma.

Proper drepping and painting were done for surgery. Under spinal anesthesia and supine position, a curvilinear suprapubic incision confined to the right side (like pfannenstiel approach) was given. Sub tissue dissection was done in layers and bladder was retracted. Bony mass was identified and excised at the base of the out growth from the parent bone. The bony mass was sent for the histopathological examination. Drain was given and wound closure was done. After that sterile dressing was done. Stitches were removed on $12^{\text {th }}$ day of post operative period. Both intra operative and post operative periods were uneventful. Follow up was done at 3 weeks and 6 weeks. Both patients were doing normal activity without any complain. The histopathological findings of the excised mass corresponded to the findings of osteochondroma which confirmed the diagnosis. (Image $1 \& 2$ ). The clinical and radiological pictures are shown figure 1 .

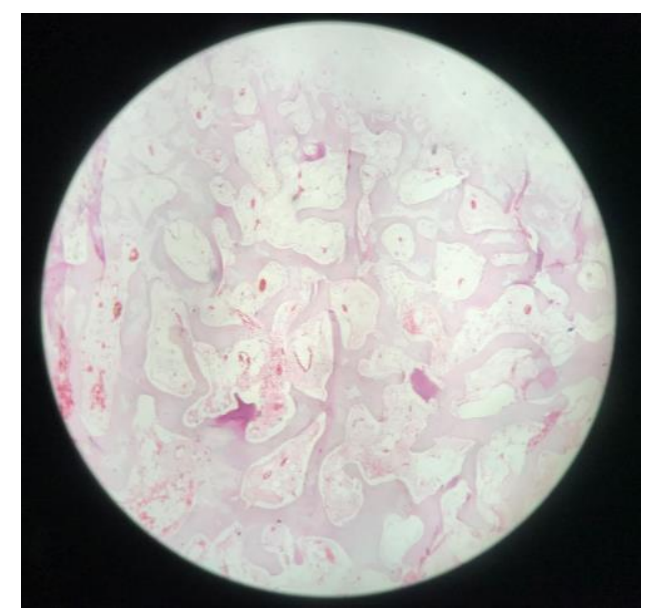

Image 1: Microscopic photograph showing cartilaginous cap with narrow elements within bony picules, $\mathrm{H} \& \mathrm{E}$

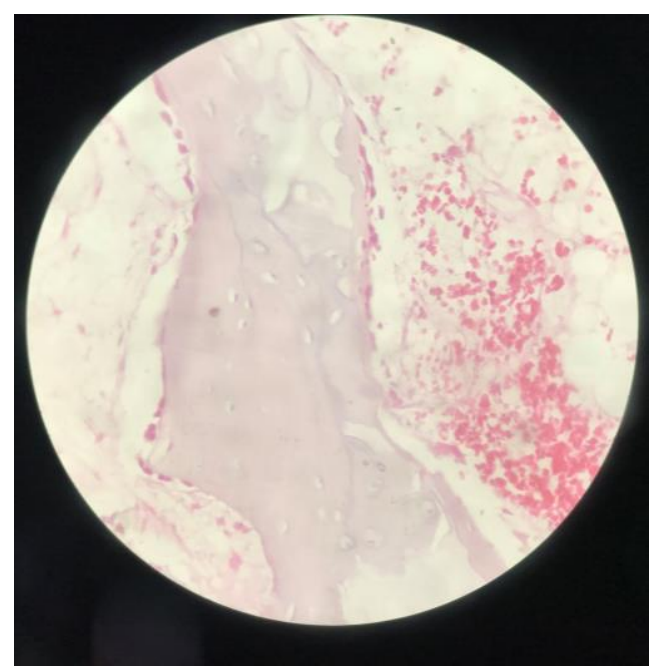

Image 2: Microscopic photograph showing chondrocytes in the cartilaginous cap of osteochondroma, $\mathrm{H} \& \mathrm{E}$

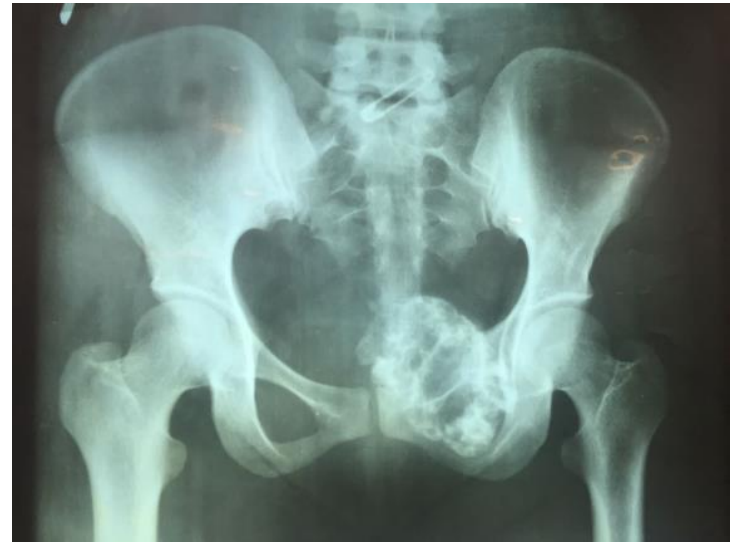

Fig 1a: Xray showing osteochondroma in pubic bone of a 40 years of female

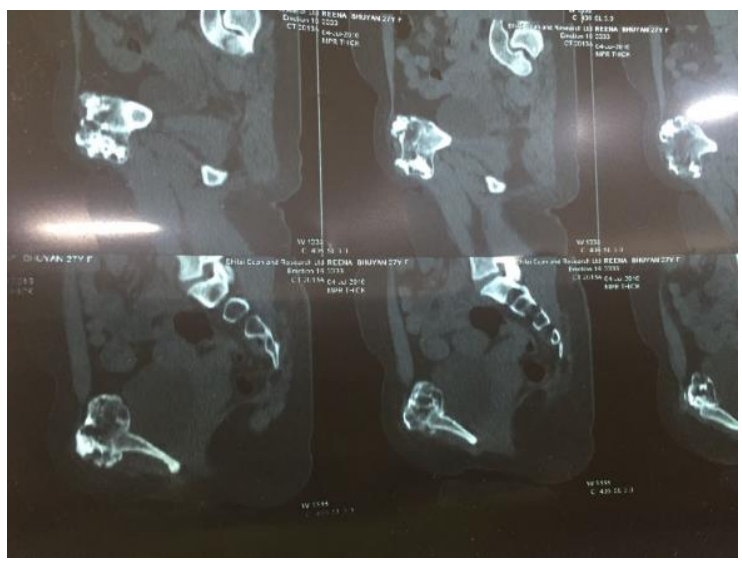

Fig 1b: CT scan showing pubic bone osteochondroma

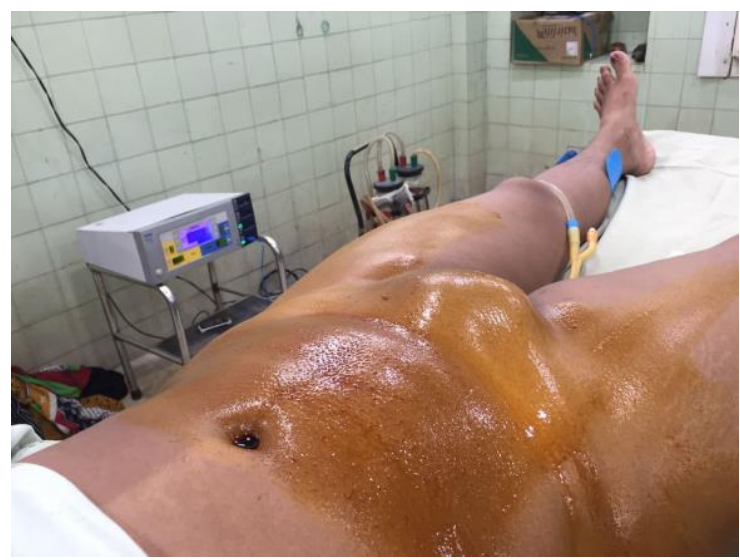

Fig 1c: Clinical picture of a 30 year old female showing pubic bone osteochondroma

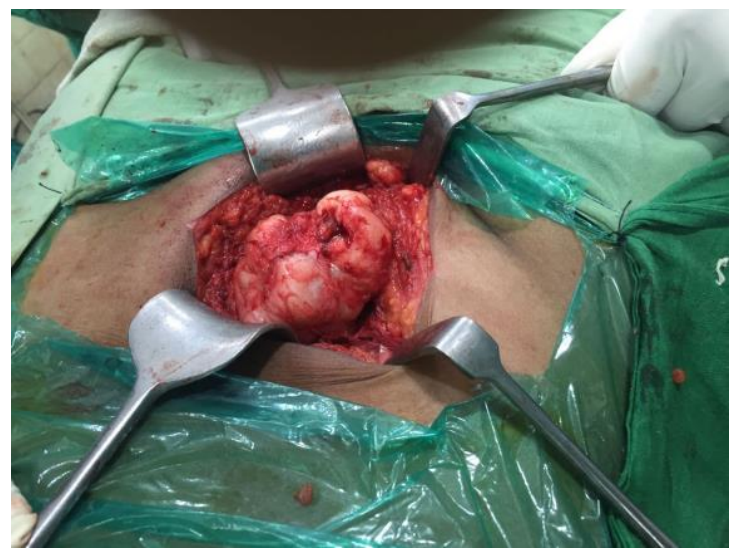

Fig 1d: intra-operative picture showing bony mass in pubic bone 


\section{Scapula bone osteochondroma}

8 cases of osteochondroma in scapula were managed by surgical procedure in this case series. Out of 8,6 were male and 2 were female. Age of the patients ranged from 15 to 46 years. All patients presented with swelling on dorsal surface of scapular body, out of which 3 had swelling towards lateral border of scapula and rest 5 had towards medial border. Along with swelling, 5 patients were complaining of mild pain. But 3 patients had no pain over swelling. All required investigations like $\mathrm{x}$ ray, CT scan, Routine bone and cardiological investigation were done before surgery. All clinical examination and radiological investigation were suggestive of osteochondroma.

Proper drepping and painting were done for surgery. Under general anesthesia and lateral decubitus position, a longitudinal incision was given over the involved area of scapular region. The length of the incision was according to the size of the lesion. Then Sub tissue dissection was done and after retracting bladder, Bony mass was identified and excised at the base of the out growth from the parent bone. The bony mass was sent for the histopathological examination. Wound closure was done and drain was given with sterile dressing. Both intra operative and post operative periods were uneventful. Stitches were removed on $12^{\text {th }}$ day of post operative period. Follow up was done at 3 weeks and 6 weeks and all patients were doing normal activity without any complain in follow up period. The findings of histopathological examination of excised mass corresponded to the osteochondroma findings which further confirmed the diagnosis. (Image $1 \& 2$ ). The clinical and radiological pictures are shown figure 2 .

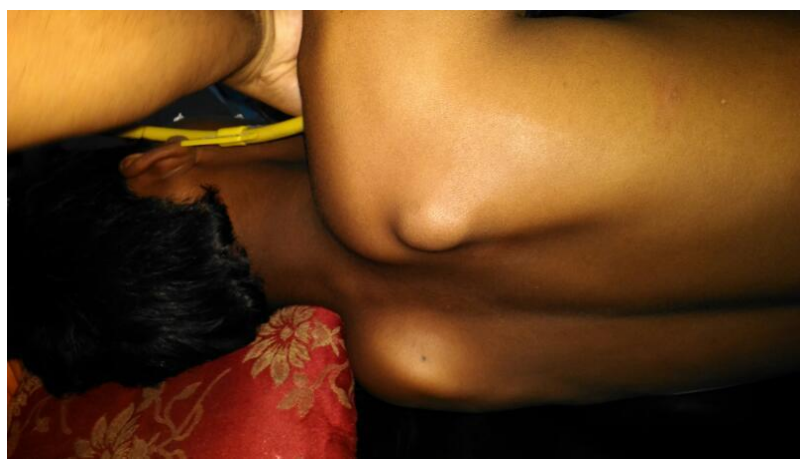

Fig 2a: clinical picture of a 35 years old male showing scapula osteochondroma

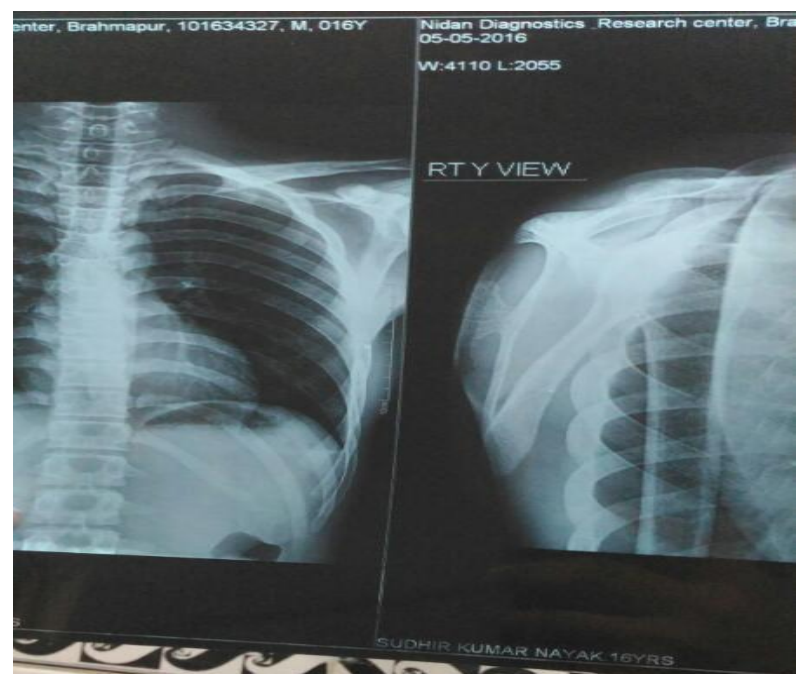

Fig 2b: X ray showing osteochondroma in scapula of a 42 year old male

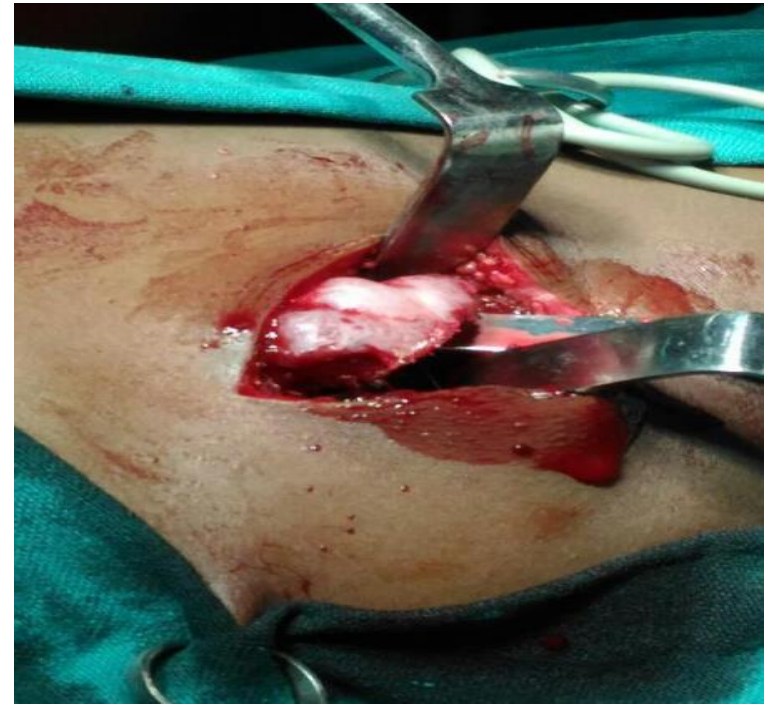

Fig 2c: Intra-operative picture showing scapula bone osteochondroma

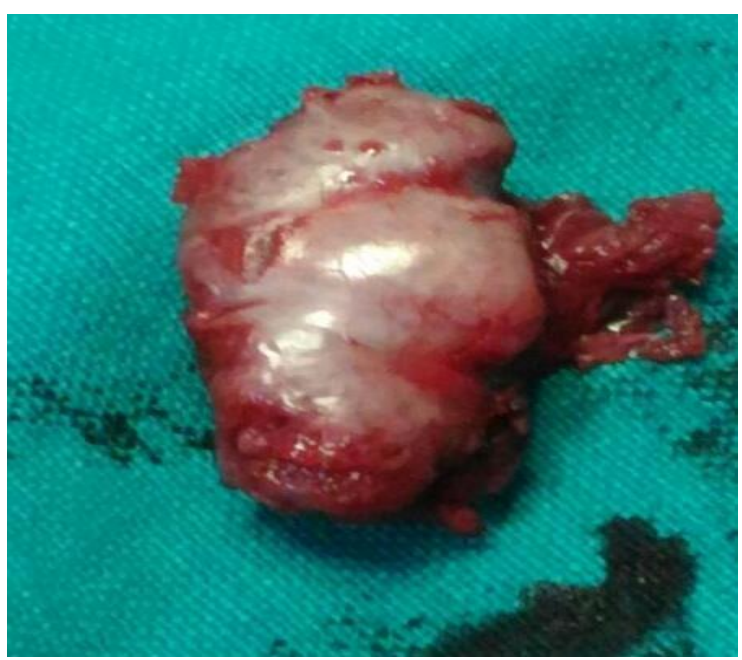

Fig 2d: bone mass ion toto after removal from parent bone

\section{Discussion}

Osteochondroma mostly occurs at long bone of lower extremity ${ }^{[5]}$. Pelvic and scapula bone involvement is rare. The exact etiology of growth is not known. But it is thought that a peripheral portion of the physis herniates from the growth plate to form the exostosis. This exostosis most commonly presents as a mass or welling without pain. Sometimes pain occurs with the mass due to pressure on the surrounding soft tissue, underlying bursitis, fracture and rarely malignant transformation ${ }^{[5]}$. In some cases, winging of scapula, restriction of free movement at shoulder joint is seen in case of osteochondroma of shoulder area ${ }^{[6,7]}$. Malignant transformation of this entity is rare and characterized by sudden increases in size of the tumor with pain. Plain radiography remains the main diagnostic modality for osteochomdroma. Grossly an osteochondroma presents as an exophytic sessile or pedunculated projection of bone. Microscopically, it consists of a cartilaginous cap superficially, a zone of endochondral ossification followed by regular trabecular bone surrounded by fatty, hematopoatic marrow with sometimes degenerative changes and calcification at cartilage cap ${ }^{[8,9]}$. Surgical excision is often curative for osteochondroma. Usually resection of the tumor is done along with stalk of tumor in case of pedunculated tumor to prevent the reoccurrence.

In our case series, we described 8 cases of osteochondroma of 
flat bone ( 2 in pubic bone and 6 in scapula bone) in which the masses were excised in-Toto surgically from the bone. All patients were followed up to 6 weeks of post operative period and all of them were doing normal activity without any complain during follow up. The result of the surgery was good in term of clinical, functional and cosmetic outcome.

\section{Conclusion}

This case series described rare cases of osteochondroma in shoulder and pubic bone. Surgical excision of the masses was done which showed good result for the osteochondroma.

\section{Acknowledgement}

Authors express their gratitude towards all study participants for their valuable time. Authors would like to extend their gratitude to the staffs of the department of Orthopaedics, MKCG Medical College, Berhampur for their contributions and technical supports.

\section{References}

1. Pongkripetch M, Sirikulchayanonta V. Analysis of bone tumors in Ramathibodi Hospital, Thailand, during 19771986: study of 652 cases. J Med Assoc Thai. 1989; 72:621-628.

2. Barbosa CS, Araujo AB, Miranda D. Incidence of primary benign and malignant neoplasms and bone pseudo tumoral lesions: an epidemiologic analysis of 585 cases diagnosed at the Faculdade de Medicina of the Universidade Federal de Minas Gerais. AMB Rev Assoc Med Bras. 1991; 37:187-192.

3. Calafiore G, Bertone C, Urgelli S, Rivera F, Maniscalco P. Osteochondroma: report of a case with atypical localization and symptomatology. Acta Biomed Ateneo Parmense. 2001; 72:91-96.

4. Mark Murphey D, James Choi J, Mark Kransdorf J et al. Imaging of Osteochondroma: Variants and Complications with Radiologic-Pathologic Correlation. Radiographics. 2000; 20:1407-1434.

5. Essadki B, Moujtahid M, Lamine A, Fikry T, Essadki O, Zryouil B. Solitary osteochondroma of the limbs: clinical review of 76 cases and pathogenic hypothesis. Acta Orthop Belg. 2000; 66:146-153.

6. Bloch AM, Nevo Y, Ben-Sira L, Harel S, Shahar E. Winging of the scapula in a child with hereditary multiple exostoses. Pediatr Neurol. 2002; 26:74-76.

7. Danielson LG, el-Haddad I. Winged scapula due to osteochondroma: report of 3 children. Acta Orthop Scand. 1989; 60:728-729.

8. Pérez D, Ramón Cano J, Caballero J, López L. Minimally-invasive resection of a scapular osteochondroma. Interact Cardiovasc Thorac Surg. 2011; 13(5):468-470.

9. Woertler K, Lindner N, Gosheger G, Brinkschmidt C, Heindel W. Osteochondroma: MR imaging of tumor related complications. Eur Radiol. 2000; 10(5):832-840. 